\title{
Noninvasive Prediction of Pulmonary Hypertension in Chronic Obstructive Pulmonary Disease by Echocardiography With \& It's Co-Relation With the Disease Severity (Hospital Based Study)
}

\author{
Muhammed Waheeb Al Obaidy ${ }^{1}$, Adnan M. Aljubouri ${ }^{1} \&$ Rana Ehsan ${ }^{2}$ \\ ${ }^{1}$ Department of Medicine, College of Medicine, University of Baghdad, Iraq \\ ${ }^{2}$ Baghdad Teaching Hospital, Baghdad, Iraq \\ Correspondence: Assistance Professor: Muhammed Waheeb Salman Al Obaidy, Department of Medicine, \\ College of Medicine, University of Baghdad, P O Box: 61265, Baghdad, Iraq. Tel: 964-790-512-9706. E-mail: \\ dmwalobaidi@comed.uobaghdad.edu.iq
}

Received: May 6, 2018 Accepted: May 20, 2018 Online Published: June 6, 2018

doi:10.5539/gjhs.v10n7p50

URL: https://doi.org/10.5539/gjhs.v10n7p50

\begin{abstract}
Background: Chronic obstructive pulmonary disease (COPD) is one of most common cause of death. Pulmonary hypertension, one of the major and under diagnosed complications of COPD which have a great impact on outcome of COAD and associated with frequent exacerbations and bad prognosis. Echocardiography provides a rapid, noninvasive, portable, and accurate method to evaluate changes related to pulmonary hypertension in COAD.
\end{abstract}

Objective Of Study: Study pulmonary artery systolic pressure and Tricuspid annular plane systolic excursion in patients with COAD by 2D ECHO Doppler and correlate them with COPD severity.

Method: Cross sectional study was conducted on 50 COPD patients in Baghdad teaching hospital (age $>40$ year) from first of January to the end of June, 2017. First, the diagnosis of COPD was confirmed and evaluated for staging by history, clinical examination, and spirometery.

All patients have undergone ECG and 2D echocardiography and systolic pulmonary artery pressure and Tricuspid Annular Plane Systolic Excursion (TAPSE) were calculated. Patients with other cardiac or respiratory problems (asthma, pulmonary TB, lung malignancy, connective tissue diseases, interstitial lung disease, and cardiac ischemia, left side heart failure) were excluded from this study.

Results: Study of PASP by TR jet with the use of 2D ECHO on 50 patients with COPD showed that 20 patients had normal echo study, mild increase in PASP was found in 15 patients, moderate 11, and severe increase in 4 patients.

Study of TAPSE by 2D ECHO showed that 35 patients had normal TAPSE values, while others 15 had abnormal values classified as mild, moderate, and severe: 3,9 , and 3 , respectively.

A significant associations between echo findings of increasing PASP and abnormal TAPSE, with decrease in FEV1, and oxygen saturation measured by pulse oximeter, duration since COPD was diagnosed and MRC dyspnea scale.

Conclusion: High incidence of pulmonary hypertension with increasing severity of COAD. Echocardiography is useful and effective tool for detection of PHT secondary to COPD.

Keywords: echocardiography, pulmonary hypertension, chronic obstructive pulmonary disease

\section{Introduction}

Chronic obstructive pulmonary disease (COPD) defined as a disease state characterized by airflow limitation which is not fully reversible (Global, 2017). COPD is a common cause of death worldwide. It is a chronic illness which worsens over time.

As may be expected from a chronic illness, periods of stable COPD are interspersed with episodes of acute exacerbations .COPD exacerbations significantly increase the rate at which the lung function deteriorates, as well as the mortality rate associated with this disease (Rycroft, 2012; Wells, Washko, Han et al., 2013). 


\section{Pulmonary Hypertension COPD}

Pulmonary hypertension is defined as a mean pulmonary pressure greater than $25 \mathrm{mmHg}$ at rest or $30 \mathrm{mmHg}$ with exercise as measured by right heart catheterization .Chronic obstructive pulmonary disease (COPD) is the most common cause of secondary pulmonary hypertension (PHT) related to lung diseases (Gologanu, Stanescu, \& Bogdan, 2012).

PHT secondary to COPD is associated with a worse prognosis of the disease, a low quality of life, as well as with a higher exacerbations frequency, and consequently with an increase in the healthcare cost of COPD patients.

Prevalence of PHT in COPD patients is currently unknown. The most important mechanisms leading to PHT are hypoxic vasoconstriction, pulmonary hyperinflation and endothelial dysfunction. PHT should be suspected in COPD patients in the presence of severe dyspnea, decline in lung function, or of severe hypoxemia (Gologanu et al., 2012).

Cor pulmonale was defined as "hypertrophy of the right ventricle resulting from diseases affecting the function and/or structure of the lungs (WHO, 1963).

\section{Pathophysiology of PHT in COPD}

The pulmonary vasculature of patients with COPD associated PHT is abnormal with increased intimal and medial thickening that cause luminal narrowing and vascular obstruction of the small pulmonary arteries (Wright, Petty, \& Thurlbeck, 1992).

These vascular changes lead to an increase in pulmonary vascular resistance (PVR) and elevation of pulmonary artery pressures (PAP). In most cases, PHT associated with COPD develops slowly over time and the pressure increases approximately $0.4 \mathrm{mmHg}$ yearly (Kessler, Faller, Weitzenblum, 2001). PHT leads to pressure overload of the right ventricle (RV). RV muscular hypertrophy occurs in response to the increased pulmonary pressures, (Dias, Assad, \& Caneo, 2002). Hypertrophy is followed by contractile dysfunction of the RV (Voelkel, Quaife, \& Leinwand, 2006). The contractile dysfunction leads to RV dilation, a decrease in cardiac output, and an increase in right sided filling pressures (Voelkel, 2006).

\section{Diagnosis of PHT in COPD}

Cardiac catheterization is the "gold standard" for the measurement of pulmonary arterial pressures. However, there are significant risks and cost issues associated with the procedure and, in any case, due to the high prevalence of COPD, it would not be feasible to perform cardiac catheterization on every patient with moderate to severe disease (Groves \& Badesch, 1996).

So Echo study is the first method for PHT screening in patients with COPD and it should be widely used, it provides a rapid, noninvasive, portable and accurate method to evaluate the right ventricle function, right ventricular filling pressure and tricuspid regurgitation.

The absence of a high PASP excludes important PHT and further unnecessary invasive evaluation. PHT secondary to COPD is usually mild, but a small proportion of patients have severe PHT, with specific characteristics, and worse prognosis (Chan \& Currie, 1987; Gologanu et al., 2012).

Using this method(echo study), several investigators have demonstrated an adequate correlation between the Doppler estimates and direct measurements with right-heart catheterization, although the accuracy of DE has been called in to question in certain clinical setting ;as it is sometimes difficult in COPD patients because of over-inflated lungs (Berger, Haimowitz, Van Tosh, Berdoff, \& Goldberg, 1985; Currie, Seward, \& Chan, 1985).

\subsection{Aim of the Study}

To study pulmonary artery systolic pressure and right ventricular function by TAPSE in patients with COPD using 2D ECHO Doppler and correlate them with severity of COPD.

\section{Methadology}

2.1 Study Design

Cross sectional study.

\subsection{Time of Study}

From first of January to the end of June, 2017.

\subsection{Site of Study}

Baghdad teaching hospital. 


\subsection{Sampling}

Fifty patients presented with signs and symptoms of COPD either admitted to the ward or coming as outpatient.

\subsection{Participants}

\section{Inclusion Criteria}

Patients with symptoms and signs of COPD ( $>40$ year) apart from exclusion criteria.

\section{Exclusion Criteria}

1)-Systemic hypertension.

2)-Cardiac diseases ,IHD, valvular disease, cardiomyopathy.

3)-Any respiratory condition like asthma apart from COPD.

4)-Any other systematic disease that lead to pulmonary hypertension such us systemic sclerosis .

5)-Patients unable to perform spirometry.

\subsection{Data Collection}

Data were collected via full medical history and complete clinical examination,and all patients were subjected to verbal agreement and the data were recorded in a pre-constructed data sheet which was included:

1)-Age, gender and occupation.

2)-Smoking: ex or current smoker, pack/year.

3)-Clinical presentation.

4)-Duration since COPD was diagnosed.

5)-MRC dyspnea scale. Dyspnea was assessed according to the scale of Medical Research Council (MRC) which reflects the functional state of the patients (Chris, 2008). It is divided into 5 grades

6)-Oxygen saturation (restrings $\mathrm{O} 2$ ) as measured by pulse oximeter.

7)-ECG findings as done by 12 leads electrocardiography.

8)-Spirometry: Use for diagnose, classification of disease severity according to GOLD guidelines (Global Initiative for Chronic Obstructive Lung Disease (GOLD) (2017).

9)-All patients were subjected to resting two-dimension transthoracic Doppler echocardiography, and M-Mode studies were done.

Right ventricular systolic pressure was estimated based on the modified Bernoulli equation and was considered to be equal to the PASP in the absence of right ventricular outflow obstruction: PASP $(\mathrm{mmHg})=$ right ventricular systolic pressure $=$ trans-tricuspid pressure gradient + right atrial pressure (RAP), where trans-tricuspid gradient is $4 v^{2}(v=$ peak velocity of tricuspid regurgitation, $\mathrm{m} / \mathrm{s})$. RAP was empirically estimated as 5,10 , or $15 \mathrm{mmHg}$ based on the variation in the size of inferior vena cava with inspiration. Pulmonary hypertension (PHT) was defined in this study as PASP $\geq 40 \mathrm{mmHg}$. PHT was classified into mild, moderate, and severe category as PASP40-49, 50-70, >70 mmHg, respectively. (Robyn, Barst, \& Michael McGoon, 2004).

It is worth noting that the only hemodynamic parameter included in the definition of PHT is the mean value of pulmonary artery pressure (mPAP). Its estimation using PASP value assessed with Doppler echocardiography is obtained through a number of formulae. One of them developed by a group of French researchers (Chemla, Castelain, \& Humbert, 2004).

$$
\mathrm{mPAP}=0.61 \times \mathrm{PASP}+2 \mathrm{mmHg}
$$

Tricuspid annular plane systolic excursion (TAPSE) the simplest echocardiography indicator of RV function, TAPSE is usually acquired by placing an M-mode cursor through the tricuspid annulus and measuring the amount of longitudinal motion of the annulus at peak systole to evaluate longitudinal RV function, the greater the descent of the base in systole, the better the RV systolic function, with value less than $16 \mathrm{~mm}$ suggestive of RV dysfunction. It is predictive of mortality in pulmonary hypertension (Sanz, 2012; Ghio, Klersy, \& Magrini, 2010).

In this study TAPSE was classified as. (Echocardiographic normal values, 2015).

Normal ( $\geq 16 \mathrm{~mm}$ ).

Mildly abnormal (13-15mm). 
Moderately abnormal (10-12mm) .

Severely abnormal $(<10 \mathrm{~mm})$.

\section{Results}

50 COPD patients were recruited in this study, with mean age group of the respondents was between (60-64 years old) in which it represents $(32.0 \%)$, the males were more than females $(86 \%$ and $14 \%)$ respectively. The majority of the patients were self-employee $(42 \%)$, the current smokers mean $=59.9 \pm 15.6$ Pack/year, while the mean of Ex-smoker was less $=52.4 \pm 12.9$ Pack/year. $62 \%$ of the COPD patients diagnosed within 1-4 years , as showing in Table 1.

Table 1. Distribution of patients according to Sociodemographic characteristics

\begin{tabular}{|c|c|c|c|}
\hline VARIABLE & & No & $\%$ \\
\hline \multirow[t]{5}{*}{ Age (years) } & $<60$ & 8 & 16.0 \\
\hline & $60---64$ & 16 & 32.0 \\
\hline & 65---69 & 13 & 26.0 \\
\hline & $=>70$ & 13 & 26.0 \\
\hline & Mean $\pm \mathrm{SD}$ (Range) & \multicolumn{2}{|c|}{$64.7 \pm 5.2(54-72)$} \\
\hline \multirow[t]{2}{*}{ Gender } & Male & 43 & 86.0 \\
\hline & Female & 7 & 14.0 \\
\hline \multirow{4}{*}{$\begin{array}{l}\text { Duration since } \\
\text { (years) }\end{array}$} & $1---4$ & 31 & 62.0 \\
\hline & 5---9 & 12 & 24.0 \\
\hline & $\Rightarrow>10$ & 7 & 14.0 \\
\hline & Mean $\pm \mathrm{SD}$ (Range) & \multicolumn{2}{|c|}{$4.6 \pm 3.2(1-12)$} \\
\hline
\end{tabular}

To assess the patients with dyspnea according to the Medical council research scale (MRC), it was found that $40 \%$ of the patients were within dyspnea score II and the rest was in score I, III and IV, while no one with dyspnea score V.

Clinically all patients (100\%) suffer from dyspnea, $72 \%$ from cough and only $20 \%$ have chest pain. Less than half $(44 \%)$ of the patients having $\geq 90 \%$ resting $\mathrm{SPO} 2$.

Pulmonary function test (FEV1) of the patients revealed that $44.0 \%$ of the patients was within moderate Forced Expiratory Volume FEV1 (59-79), 36\% was mild, $12 \%$ was severe and only $8 \%$ were very severe.

Figures 1 and 2 show that RA enlargement was found in $32 \%$ of the patients by the Echo examination, $30 \%$ have RV enlargement. $40 \%$ of the patients have normal PASP and the less one was severe increase in PASP (8\%). $70 \%$ of the patients within normal TAPSE and $6 \%$ with severely abnormal TAPSE. 


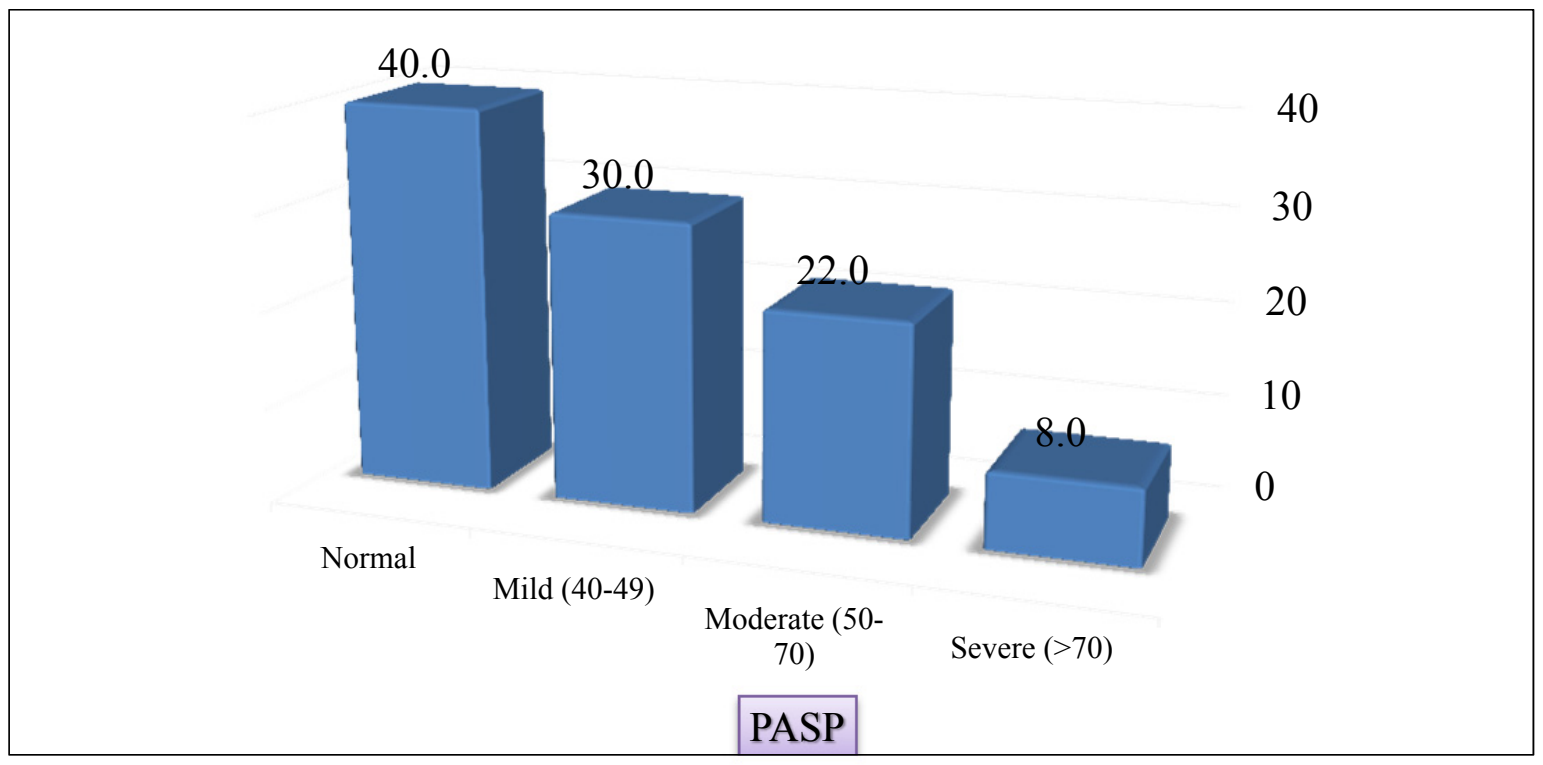

Figure 1. Distribution of the patients according to Pulmonary artery systolic pressure (PASP)

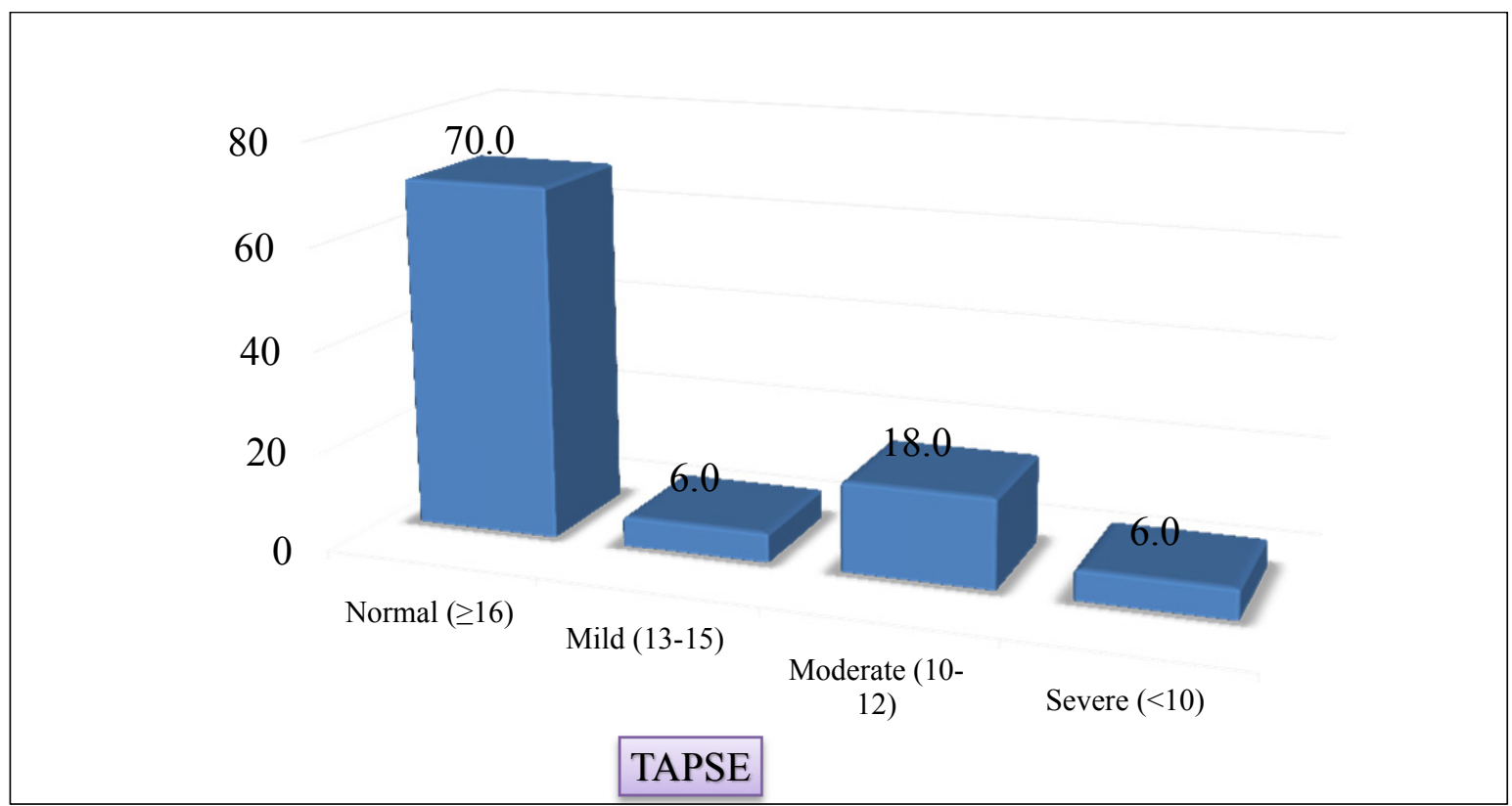

Figure 2. Distribution of the patients according to Tricuspid annular plane systolic excursion (TAPSE)

It had been found that there is a highly significant association ( $\mathrm{p}$ value $<0.001$ ) between the Echo findings (PASP and TAPSE) and COPD severity by FEV1. 
Table 2. The association between FEV1 with Echo findings

\begin{tabular}{|c|c|c|c|c|c|c|}
\hline \multirow{2}{*}{\multicolumn{2}{|c|}{ VARIABLES }} & \multicolumn{4}{|l|}{ FEV1 } & \multirow{2}{*}{-P value } \\
\hline & & Mild ( $\geq 80)$ & Moderate (50-79) & Severe (30-49) & Very severe $(<\mathbf{3 0})$ & \\
\hline \multirow{4}{*}{ PASP } & Normal & 18 & 2 & - & - & \multirow[t]{4}{*}{$<0.001 *$} \\
\hline & Mild (40-49) & - & 15 & - & - & \\
\hline & Moderate (50-70) & - & 5 & 6 & - & \\
\hline & Severe $(>70)$ & - & - & - & 4 & \\
\hline \multirow{4}{*}{ TAPSE } & Normal $(\geq 16)$ & 18 & 17 & - & - & \multirow[t]{4}{*}{$<0.001^{*}$} \\
\hline & Mild (13-15) & - & 2 & 1 & - & \\
\hline & Moderate (10-12) & - & 3 & 5 & 1 & \\
\hline & Severe $(<10)$ & - & - & - & 3 & \\
\hline
\end{tabular}

*Significant difference between proportions using Pearson Chi-square test at 0.05 level.

Table 3 reveals that there is a highly significant $(<0.001)$ association between Echo findings (abnormal PASP and TAPSE) with Duration of the COPD disease, Resting SPO2 and MRC Dyspnea score.

Table 3. The relation between Echo findings with Duration of the COPD disease, Resting SpO2 and MRC Dyspnea score

\begin{tabular}{|c|c|c|c|c|c|}
\hline \multirow{2}{*}{\multicolumn{2}{|c|}{ VARIABLE }} & \multicolumn{3}{|c|}{ Duration since COPD diagnosis (years) } & \multirow{3}{*}{$\begin{array}{c}\text {-P value } \\
<0.001 *\end{array}$} \\
\hline & & \multirow{2}{*}{$\begin{array}{l}\mathbf{1 - - 4} \\
19\end{array}$} & \multirow{2}{*}{$\begin{array}{l}5--9 \\
1\end{array}$} & \multirow{2}{*}{$\begin{array}{l}\Rightarrow>10 \\
-\end{array}$} & \\
\hline \multirow{4}{*}{ PASP } & Normal & & & & \\
\hline & Mild (40-49) & 7 & 7 & 1 & \\
\hline & Moderate $(50-70)$ & 5 & 3 & 3 & \\
\hline & Severe $(>70)$ & - & 1 & 3 & \\
\hline \multirow{4}{*}{ TAPSE } & Normal $(\geq 16)$ & 26 & 8 & 1 & \multirow[t]{4}{*}{$<0.001^{*}$} \\
\hline & Mild (13-15) & 3 & - & - & \\
\hline & Moderate (10-12) & 2 & 3 & 4 & \\
\hline & Severe $(<10)$ & - & 1 & 2 & \\
\hline \multicolumn{6}{|c|}{ *Significant difference between proportions using Pearson Chi-square test at 0.05 level. } \\
\hline \multirow{2}{*}{\multicolumn{2}{|c|}{ VARIABLE }} & \multicolumn{3}{|c|}{ Resting SpO2 } & vlue \\
\hline & & $=>90 \%$ & 85---89\% & $<\mathbf{8 5 \%}$ & r vaiue \\
\hline \multirow{4}{*}{ PASP } & Normal & 20 & - & - & \multirow[t]{4}{*}{$<0.001 *$} \\
\hline & Mild (40-49) & 2 & 12 & 1 & \\
\hline & Moderate (50-70) & - & 8 & 3 & \\
\hline & Severe $(>70)$ & - & - & 4 & \\
\hline \multirow{4}{*}{ TAPSE } & Normal $(\geq 16)$ & 22 & 12 & 1 & \multirow[t]{4}{*}{$<0.001 *$} \\
\hline & Mild (13-15) & - & 3 & - & \\
\hline & Moderate (10-12) & - & 5 & 4 & \\
\hline & Severe $(<10)$ & - & - & 3 & \\
\hline
\end{tabular}

*Significant difference between proportions using Pearson Chi-square test at 0.05 level. 


\begin{tabular}{|c|c|c|c|c|c|c|}
\hline \multirow{2}{*}{\multicolumn{2}{|c|}{ VARIABLE }} & \multicolumn{4}{|c|}{ MRC dyspnea score (I--V) } & \multirow{2}{*}{-P value } \\
\hline & & $\overline{\mathbf{I}}$ & II & III & IV & \\
\hline \multirow{4}{*}{ PASP } & Normal & 8 & 12 & - & - & \multirow[t]{4}{*}{$<0.001 *$} \\
\hline & Mild (40-49) & - & 8 & 7 & - & \\
\hline & Moderate (50-70) & - & - & 8 & 3 & \\
\hline & Severe $(>70)$ & - & - & 1 & 3 & \\
\hline \multirow{4}{*}{ TAPSE } & Normal ( $\geq 16)$ & 8 & 20 & 7 & - & \multirow[t]{4}{*}{$<0.001 *$} \\
\hline & Mild (13-15) & - & - & 2 & 1 & \\
\hline & Moderate (10-12) & - & - & 6 & 3 & \\
\hline & Severe $(<10)$ & - & - & 1 & 2 & \\
\hline
\end{tabular}

*Significant difference between proportions using Pearson Chi-square test at 0.05 levels.

\section{Discussion}

The current study concluded that the mean age of the patients was $64.7 \pm 5.2$ years, which is in accord with that found by Ozben et al. (2015) study in Turkey. When the mean age of the patients was (64.2 \pm 10.9 ). But not similar to that found in Soliman et al. (2015) study in Egypt, where the mean age was 59 \pm 9.16 years. Also not similar to Forfia et al. (2006) study in USA, study when the mean age was $55 \pm 15$.In a study done by Gartman et al. (2012) study in USA, and Fayngersh et al. (2011). They showed that PHT might be described in patients with advanced age, however they asked either this association is attributable to age alone, or other co morbidities contributing to PHT in the elderly.

The present study showed male sex predominance (86\%) and this might be directly related to COPD prevalence where it is more common in males than females due to smoking habits, and this is consistent with GOLD 2013 as it showed male predominance of COPD.

The most important risk factor for COPD is cigarette smoking. Approximately $20 \%$ of regular cigarette smokers develop progressive airflow obstruction at some time during life; patients with COPD usually have smoking history of at least 20 pack-years (Viegi \& Scognamiglio, 2001)., which is in agreement with the present study

\subsection{Mrc Dyspnea Score}

The recent study showed that most patients with MRC score II of $40 \%$. And there is significant correlation between increase MCR dyspnea score and echo parameters of PHT .This finding as similar to the results of Tanaka et al. (2013) study in Japan, as it showed that MRC dyspnea score was higher in subjects with echocardiography findings suggestive of PHT than those without.

\subsection{ECG Finding}

The current study showed that the main group in the ECG finding was normal and the predominant changes were $\mathrm{P}$ pulmonale and right axis deviation which is in agreement with other Iraqi study by Amjed H. Abbas ${ }^{(39)}$ Moreover it is consistent with a study by Rodman et al. (Rodman, 1990).

\subsection{Pulmonary Function Test (FEV1)}

In this study we found that $44.0 \%$ of the patients was within moderate FEV1, $36 \%$ was mild, $12 \%$ was severe and only $8 \%$ were very severe .This finding is close to results of Higham et al study in UK (Higham, 2001), in which, $25 \%$ were mild while $43 \%$ were moderate. While in a study done by Amardip Rajput et al in India (Amardip Rajput, 2016), with the same patient's number (50) they showed that (16\%) patients had moderate grade COPD, $(60 \%)$ patients had severe grade COPD, $(24 \%)$ had very severe grade COPD.

\subsection{Echo Finding}

Echo finding: The present study concludes that $30 \%$ of the COPD patients have right ventricular dilatation, similarly to that found by Necla Özer et al. (2001), and reported that with COPD, the development of PHT leads to right ventricular dilation, right ventricular systolic and diastolic dysfunction.

In our study of PASP by 2D ECHO we found mild PHT in 15 patients out of 50 while moderate PHT in remaining 11 patients, while 4 patients with severe PHT ,so the increase in PASP was present in $60 \%$ of the patients which are same that revealed by Gupta et al. (2011) study in India, in their study of echocardiography evaluation of COPD in 
40 patients when it was (63\%), but it is more than that mentioned by Sultan et al. (2009) study in Iraq, when they found that PASP was elevated in only $36 \%$ of total COPD patients. Moreover it is more that found by Weitzenblum et al in France, and Burgess et al in United Kingdom' studies in which the PHT was found in 35\% of patients with COPD and $34.4 \%$ respectively. Correlation of PASP with FEV1 was done in our study, it came out to be statistically significant $(\mathrm{p}<0.001)$ in similarity with study by Rathi et al. study in India, and similar to study of Sultan et al. (2009) and Higham et al. (2001). In present study, there was highly significant association between the frequencies of PHT in very severe COPD. While in a study by Jain et al. in India, the moderate to severe PHT was more commonly seen in COPD Grade 3 and Grade 4 patient as compared to COPD grade 2 patients.

Also we found that increase PASP was more frequently with decreasing $\mathrm{O} 2$ saturation and the association were statistically significant. This finding was in similarities with study by Sultan et al. (2009) in Iraq, Burgess et al. (2002) study in UK reported significant association between increased PASP with decreasing FEV1 but they did not compare the findings with $\mathrm{O} 2$ saturation.

The current study showed that $70 \%$ of the patients have normal TAPSE which is not concordant with the Rathi et al. (2015), when the studies of TAPSE by 2D ECHO showed that $80(80 \%)$ patients had abnormal TAPSE value while $20(20 \%)$ patients had normal value, this is may be due to different in sample size where their study done on 100 patients and patients with severe COPD were excluded from their study. Correlation of TAPSE with COPD staging was done in our study. It came out to be statistically significant $(\mathrm{p}<0.001)$, similar to the result of Rathi et al. (2015).

Chaisson et al. (2012), Chelliah et al. (2012), Forfia et al. (2006), and Charlotte Uggerhøj et al. (2010), studies in USA, conducted about efficacy of TAPSE in predicting RV function in COPD patients . Saxena et al. (2006), showed (TAPSE) is a useful measurement in determining right ventricular systolic function regardless of pulmonary artery pressures in a study of 52 patients.

\section{Conclusions}

Severity of COPD correlated very well with proportionate changes in PASP and RV function assessed by TAPSE (pulmonary hypertension).

There is highly significant correlation between increase PASP and abnormal TAPSE values with MRC dyspnea scale, resting SPO2 and duration since COPD diagnosed.

\section{Competing Interests Statement}

The authors declare that there are no competing or potential conflicts of interest.

\section{References}

Amardip, R., Virendra, C. P., Swati, C. A., Chinmay, K., Jayesh, S. S. (2016). Echocardiographic Evaluation of Patients with Chronic Obstructive Pulmonary Disease and Its Relation with the Severity of the Disease. RJPBCS, 7(4), 446-52.

Amjed, H. A. (2014). Chronic Obstructive Pulmonary Disease: Impact Of Hypoxia. Iraq, Karbala J. Med., 7(2), 1971-79.

Barst, R. J., McGoon, M., Torbicki, A., Sitbon, O., Krowka, M. J., Olschewski, H., \& Gaine, S. (2004). Diagnosis and differential assessment of pulmonary arterial hypertension. Journal of the American College of Cardiology, 43(12 Supplement), S40-S47. https://doi.org/10.1378/chest.126.4.1313

Berger, M., Haimowitz, A., Van Tosh, A., Berdoff, R. L., \& Goldberg, E. (1985). Quantitative assessment of pulmonary hypertension in patients with tricuspid regurgitation using continuous wave Doppler ultrasound. $J$ Am CollCardiol, 6, 359-365. https://doi.org/10.1016/S0735-1097(85)80172-8

Brenner, G. M., \& Stevens, C. W. Pharmacology (4th ed.). Philadelphia: Elsevier Saunders.

Burgess, M. I., Mogulkoc, N., Bright-Thomas, R. J., Bishop, P., Egan, J. J., \& Ray, S. G. (2002). Comparison of echocardiographic markers of right ventricular function in determining prognosis in chronic pulmonary disease. Journal of the American Society of Echocardiography, 15(6), 633-639. https://doi.org/10.1067/mje.2002.118526

Chaisson, N. F., Mathai, S. C., \& Hassoun, P. M. (2012) Assessment of Tricuspid Annular Plane Systolic Excursion (tapse) By 2d And M-Mode Echocardiography in Pulmonary Arterial Hypertension Patients. Am J $\begin{array}{lllll}\text { Respiratory Critical } & \text { Care } & \text { Med, } & \text { 2(185), } & \text { A3459. }\end{array}$ https://doi.org/10.1164/ajrccm-conference.2012.185.1_MeetingAbstracts.A3459 
Chan, K. L., Currie, P. J., Seward, J. B., Hagler, D. J., Mair, D. D., \& Tajik, A. J. (1987). Comparison of three Doppler ultrasound methods in the prediction of pulmonary artery pressure. $J$ Am CollCardiol., 9, 549-54. https://doi.org/10.1016/S0735-1097(87)80047-5

Charlotte Uggerhøj, A. et al. (2010). Echocardiographic screening for pulmonary hypertension in COPD patients. Special Issue: Abstracts and proceedings from IV Scandinavian COPD Research Symposium, Nov. The Clinical Respiratory Journal, 5(Supplements 1), 9.

Chelliah, A., Holland, B. J., Rosenzweig, E. B., Andrews, H., Feng, M., Misra, N., \& Lai, W. W. (2012). Tricuspid Annular Plane Systolic Excursion (TAPSE) Correlates with Morbidity and Hemodynamic Parameters in Pediatric Patients with Pulmonary Arterial Hypertension. InB64. Right ventricle in pulmonary vascular disease, American Thoracic Society; may (pp. A3448-A3448). https://doi.org/10.1164/ajrccm-conference.2012.185.1_MeetingAbstracts.A3448

Chris, S. (2008). The MRC breathlessness scale.Oxford Journals Medicine. Occup.Med. (Lond), 58, 226-227. https://doi.org/10.1093/occmed/kqm162

Currie, P. J., Seward, J. B., Chan, K. L., Fyfe, D. A., Hagler, D. J., .. Tajik, A. J.(1985). Continuous wave Doppler determination of right ventricular pressure: a simultaneous Doppler-catheterization study in 127 patients. $J$ Am Coll Cardiology, 6, 750-756. https://doi.org/10.1016/S0735-1097(85)80477-0

Dias, C. A., Assad, R. S., Caneo, L. F., et al. (2002). Reversible pulmonary trunk banding. II. An experimental model for rapid pulmonary ventricular hypertrophy. J Thorac Cardiovasc Surg, 124, 999-1006. https://doi.org/10.1067/mtc.2002.124234

Echocardiographic normal values [Internet] (2015). November /20.Available from https://www.echopedia.org/wiki/Normal_Values\#bibkey_ASE.

Fayngersh, V., Drakopanagiotakis, F., McCool, F. D., \& Klinger, J. R. (2011). Pulmonary hypertension in a stable community-based COPD population. Lung, 189(5), 377. https://doi.org/10.1007/s00408-011-9315-2

Forfia, P. R., Fisher, M. R., Mathai, S. C., Housten-Harris, T., Hemnes, A. R., Borlaug, B. A., ... \& Girgis, R. E. (2006). Tricuspid annular displacement predicts survival in pulmonary hypertension. American journal of respiratory and critical care medicine, 174(9), 1034-1041. https://doi.org/10.1164/rccm.200604-547OC

Gartman, E. J., Blundin, M., Klinger, J. R., Yammine, J., Roberts, M. B., \& McCool, F. D. (2012). Initial risk assessment for pulmonary hypertension in patients with COPD. Lung, 190(1), 83-89. https://doi.org/10.1007/s00408-011-9346-8

Ghio S, Klersy C, Magrini G, et al. (2010). Prognostic relevance of the echocardiographic assessment of right ventricular function in patients with idiopathic pulmonary arterial hypertension. Int J Cardiol., 140, 272-278. https://doi.org/10.1016/j.ijcard.2008.11.051

Global Initiative for Chronic Obstructive Lung Disease (GOLD). (2017). Global Strategy for the Diagnosis, Management and Prevention of COPD (2017). Retrieved from http://www.goldcopd.org.

Global initiative for chronic obstructive lung disease. (2017). Global strategy for the diagnosis, management and prevention of chronic obstructive lung disease. Report .

Gologanu, D. A. N. I. E. L. A., Stanescu, C. R. I. S. T. I. N. A., \& Bogdan, M. A. (2012). Pulmonary hypertension secondary to chronic obstructive pulmonary disease. Romanian journal of internal medicine $=$ Revue roumaine de medecine interne, 50(4), 259-268.

Groves, B. M.., \& Badesch, D. B. (1996). Cardiac catheterization of patients with pulmonary hypertension. In A. J. Peacock (Ed.), Pulmonary circulation. London: Chapman Hall: 51 - 67.

Gupta, N. K., Agrawal, R. K., Srivastav, A. B., \& Ved, M. L. (2011). Echocardiographic evaluation of heart in chronic obstructive pulmonary disease patient and its co-relation with the severity of disease. Lung India: official organ of Indian Chest Society, 28(2), 105.

Higham, M. A., Dawson, D., Joshi, J., Nihoyannopoulos, P., \& Morrell, N. W. (2001). Utility of echocardiography in assessment of pulmonary hypertension secondary to COPD. European Respiratory Journal, 17(3), 350-355. https://doi.org/10.1183/09031936.01.17303500

Kessler, R., Faller, M., Weitzenblum, E., et al. (2001). "Natural history" of pulmonary hypertension in a series of 131 patients with chronic obstructive lung disease. Am J RespirCrit Care Med, 164, 219-24. https://doi.org/10.1164/ajrccm.164.2.2006129 
Ozben, B. E. S. T. E., Eryuksel, E., Tanrikulu, A. M., Papila, N., Ozyigit, T., Celikel, T., \& Basaran, Y. (2015). Acute exacerbation impairs right ventricular function in COPD patients. Hellenic J Cardiol, 56, 324-331.

Özer, N., Tokgözoğlu, L., Çöplü, L., \& Kes, S. (2001). Echocardiographic evaluation of left and right ventricular diastolic function in patients with chronic obstructive pulmonary disease. Journal of the American Society of Echocardiography, 14(6), 557-561. https://doi.org/10.1067/mje.2001.111474

Rathi, C., Wanjari, A., \& Acharya, S. (2015). Pulmonary hypertension in mild-moderate COPD: an early link. Journal of Evidence based Medicine and Healthcare, 2(42), 7330-40.

Reilly, J. J., Silverman, E. K., \& Shapiro, S. D. (2013). Chronic obstructive pulmonary disease. In: Loscalazo J, Fauci AS, Kasper DL, et al. (Eds.), Harrison's Pulmonary and Critical Care Medicine (2nd ed., p. 178). McGraw-Hill.

Rodman, D. M., Lowenstein, S. R., \& Rodman, T. (1990). The electrocardiogram in chronic obstructive pulmonary disease. The Journal of emergency medicine, 8(5), 607-615.

Rubin, L. J. (2004). Diagnosis and management of pulmonary arterial hypertension: ACCP evidence-based clinical practice guidelines. Chest; 126, 7S-10S. https://doi.org/10.1378/chest.126.1_suppl.7S

Rudski, L. G., Lai, W. W., Afilalo, J., Hua, L., Handschumacher, M. D., Chandrasekaran, K., ... \& Schiller, N. B. (2010). Guidelines for the echocardiographic assessment of the right heart in adults: a report from the American Society of Echocardiography: endorsed by the European Association of Echocardiography, a registered branch of the European Society of Cardiology, and the Canadian Society of Echocardiography. Journal of the American Society of Echocardiography, 23(7), 685-713.

Rycroft, C. E., Heyes, A., Lanza, L., \& Becker, K. (2012). Epidemiology of chronic obstructive Pulmonary disease: a literature review. Int $J$ Chronic Obstructive Pulmonary Disease, 7, 457-494. https://doi.org/10.2147/COPD.S32330

Sanz, J., Conroy, J., \& Narula, J. (2012). Imaging of the right ventricle clinical. Cardiology, 30, $189-203$. https://doi.org/10.1016/j.ccl.2012.03.001

Saxena, N. et al. (2006). Tricuspid annular systolic velocity: a useful measurement in determining right ventricular systolic function regardless of pulmonary artery pressures. Echocardiography, 23(9), 750-5. https://doi.org/10.1111/j.1540-8175.2006.00305.x

Shujaat, A., Minkin, R., \& Eden, E. (2007). Pulmonary hypertension and chronic cor pulmonale in COPD. Int J Chron Obstruct Pulmon Dis., 2(3), 273-282.

Soliman, M., Heshmat, H., Amen, Y., Aboelhassan, U. E., \& Mahmod, K. (2015). Detection of right sided heart changes and pulmonary hypertension in COPD patients. Egyptian Journal of Chest Diseases and Tuberculosis, 64(2), 335-341. https://doi.org/10.1016/j.ejcdt.2014.12.004

Sultan, K. M., Hussain, M. F., \& Ismael, A. A. (2009). The relation of echocardiographic findings to pulmonary function tests in patients with chronic obstructive pulmonary disease. J Fac Med Baghdad; 51(1), 17-22.

Tanaka, Y., Hino, M., Mizuno, K., \& Gemma, A. (2013). Evaluation of right ventricular function in patients with COPD. Respiratory care, 58(5), 816-823.

Viegi, G., Scognamiglio, A., Baldacci, S., Pistelli, F., \& Carrozzi, L. (2001). Epidemiology of chronic obstructive pulmonary disease (COPD). Respiration, 68(1), 4-19. https://doi.org/10.1159/000050456

Voelkel NF, Quaife RA, Leinwand LA, et al. (2006). Right ventricular function and failure: report of a national heart, lung, and blood institute working group on cellular and molecular mechanisms of right heart failure. Circulation, 114, 1883-91. https://doi.org/10.1161/CIRCULATIONAHA.106.632208

Voelkel, N. F., Quaife, R. A., Leinwand, L. A., et al. (2006). Right ventricular function and failure: report of a national heart, lung, and blood institute working group on cellular and molecular mechanisms of right heart failure. Circulation, 114, 1883-91. https://doi.org/10.1161/CIRCULATIONAHA.106.632208

Weitzenblum, E., Hirth, C., Ducolone, A., Mirhom, R., Rasaholinjanahary, J., \& Ehrhart, M. (1981). Prognostic value of pulmonary artery pressure in chronic obstructive pulmonary disease. Thorax, 36(10), 752-758. https://doi.org/10.1136/thx.36.10.752

Wells, J. M., Washko, G. R., Han, M. K., Abbas, N., Nath, H., Mamary, A. J., .. \& Beaty, T. H. (2012). Pulmonary arterial enlargement and acute exacerbations of COPD. New England Journal of Medicine, 367(10), 913-921.

WHO expert committee report. (1963). World Health Organization Chronic cor pulmonale. A report of the expert 
committee. Circulation, 27, 594-8. https://doi.org/10.1161/01.CIR.27.4.594

Wright, J. L., Petty, T., \& Thurlbeck, W. M. (1992). Analysis of the structure of the muscular pulmonary arteries in patients with pulmonary hypertension and COPD: National Institutes of Health nocturnal oxygen therapy trial. Lung, 170, 109-24. https://doi.org/10.1007/BF00175982

\section{Copyrights}

Copyright for this article is retained by the author(s), with first publication rights granted to the journal.

This is an open-access article distributed under the terms and conditions of the Creative Commons Attribution license (http://creativecommons.org/licenses/by/4.0/). 